\title{
Attapulgite Nanofiber-Cellulose Nanocomposite with Core-Shell Structure for Dye Adsorption
}

\author{
Xiaoyu Chen, Xiaoxue Song, and Yihe Sun \\ School of Material Engineering, Jinling Institute of Technology, Nanjing 211169, China \\ Correspondence should be addressed to Xiaoyu Chen; chxy@jit.edu.cn
}

Received 25 March 2016; Revised 22 May 2016; Accepted 31 May 2016

Academic Editor: Ming Zhang

Copyright ( 2016 Xiaoyu Chen et al. This is an open access article distributed under the Creative Commons Attribution License, which permits unrestricted use, distribution, and reproduction in any medium, provided the original work is properly cited.

\begin{abstract}
Nanocomposite particle used for adsorption has attracted continuous attention because of large specific surface area and adjustable properties from nanocomponent. Herein nanocomposite particle with cellulose core and attapulgite nanofibers shell was prepared. The size of cellulose core was about $2 \mathrm{~mm}$ and the thickness of nanofibers shell is about $300 \mu \mathrm{m}$. Adsorption capacity of nanocomposite particle to methylene blue can reach up to $11.07 \mathrm{mg} \mathrm{L}^{-1}$ and the best adsorption effect occurs at $\mathrm{pH}=8$; $\mathrm{pseudo}$-firstorder equation and the Langmuir equation best describe the adsorption kinetic and isotherm, respectively; repeated adsorptiondesorption experimental results show that $94.64 \%$ of the original adsorption capacity can be retained after being reused three times.
\end{abstract}

\section{Introduction}

Attapulgite nanofiber is a kind of hydrated octahedral layered magnesium aluminum silicate with diameter of $20 \mathrm{~nm}$ and length of several hundred nanometers to several micrometers $[1,2]$. Theoretical formula of attapulgite nanofiber is $\left(\mathrm{Al}_{2} \mathrm{Mg}_{2}\right) \mathrm{Si}_{8} \mathrm{O}_{20}(\mathrm{OH})_{2}\left(\mathrm{OH}_{2}\right)_{4} \cdot 4 \mathrm{H}_{2} \mathrm{O}$ [3]. Due to large specific surface area, attapulgite nanofiber has high sorption ability and is widely used in decoloring, drying, removing heavy metal ions or organic contaminants, and other fields $[4,5]$. Attapulgite nanofiber possesses permanent negative charges and exchangeable cations [2]. Used as dye adsorbent, attapulgite nanofiber can remove cationic dye such as methylene blue from water. But when added to water, attapulgite nanofibers suspend in water and are difficult to be separated from water after adsorption. The suspended attapulgite will cause secondary pollution to the water and cannot be reused [6]. Therefore, finding an excellent carrier for attapulgite is important to avoid secondary pollution and to reuse attapulgite.

Polymer nanocomposites are composites of particlefilled polymers for which at least one dimension of the dispersed particles is in the nanometer range [7-9]. Polymer nanocomposites containing attapulgite nanofiber have been prepared, in which polymer exists as hydrogel and attapulgite nanofibers are embedded in the hydrogel [10, 11]. This hydrogel can be used as super adsorbent and adsorbent for heavy metal ions $[10,11]$.

Adsorption usually occurred on the surface of absorbent $[12,13]$. Particle adsorbents have large surface area, which leads to high adsorption ability. Core-shell structure with adsorbent on the shell has low cost and is favorable for particle adsorbent to adsorb dye. Cellulose is one of the most abundant biopolymers in nature $[14,15]$. Nanocomposite particle with cellulose core and attapulgite nanofiber shell has never been reported. But cellulose is difficult to dissolve in common solvent to form cellulose bead. $\mathrm{NaOH} /$ urea solution is a "green" and cheap method to dissolve cellulose with no pollution [16].

In this study, we combined attapulgite nanofiber and cellulose to prepare a low-cost adsorbent for water treatment. We prepared cellulose bead by dissolving cellulose in $\mathrm{NaOH} /$ urea solution as core to afford necessary strength. Attapulgite nanofibers were coated on cellulose bead as shell to adsorb dye. Coated attapulgite shell can prevent second pollution of attapulgite in water. The structure, adsorption 
behaviors, and reusability of this nanocomposite were investigated.

\section{Materials and Methods}

2.1. Materials. $\mathrm{NaOH}, \mathrm{HCl}, \mathrm{CaCl}_{2}$, urea, acetic acid, methylene blue (methylthioninium chloride $\mathrm{C}_{16} \mathrm{H}_{18} \mathrm{~N}_{3} \mathrm{SCl}$ ), and other reagents used in the current work are all A.R. grade reagents. Attapulgite is provided by Jiangsu dianjinshi Au soil Mining Industry Co., Ltd. Distilled water is used in all experiments. Scoured cotton was used in this study as cellulose provided by Xuzhou weicai hygiene material factory Co., Ltd. Sodium alginate is provided by Shanghai Qingxi Chemical Technology Co., Ltd.

2.2. Preparation of the Nanocomposite Particle. Cellulose was dissolved in $\mathrm{NaOH} /$ urea solution using reported method [17]. Solution of $\mathrm{NaOH}(7 \mathrm{~g})$, urea $(12 \mathrm{~g})$, and $\mathrm{H}_{2} \mathrm{O}(81 \mathrm{~mL})$ was cooled to $-12^{\circ} \mathrm{C}$; then $2 \mathrm{~g}$ scoured cotton was immediately added to above solution; then scoured cotton was stirred vigorously for $2 \mathrm{~min}$ to obtain a transparent cellulose solution. The resulting solution was dropped into $20 \mathrm{wt} \%$ acetic acid solution to form cellulose bead; then the cellulose bead was immersed in water for three days to remove urea and $\mathrm{NaOH}$ in bead.

Attapulgite powder was dispersed in $2.5 \mathrm{wt} \%$ sodium alginate solutions with agitation and the mass ratios of sodium alginate/attapulgite are $1: 0,1: 1,0.83: 1$, and $0.5: 1$. Then cellulose bead was coated with above suspension and dipped in $\mathrm{CaCl}_{2}$ solution to cross-link the sodium alginate. The coated bead was washed with deionized water and dried in an oven at $50^{\circ} \mathrm{C}$ for $48 \mathrm{~h}$ to get dried composite particle. Composite particles with alginate/attapulgite mass ratios of $1: 0,1: 1,0.83: 1$, and $0.5: 1$ were labeled as $\mathrm{AC} 0$, $\mathrm{AC1}, \mathrm{AC} 2$, and $\mathrm{AC} 3$, respectively. In addition, attapulgite and cellulose solution mixture was dropped into $20 \mathrm{wt} \%$ acetic acid solution to form bead coded as AC4.

2.3. Morphology and Structure of Composite Particle. Surface morphology of composite bead was observed by scanning electron microscopy (SEM, SU8010, Hitachi). Microstructure of composite particles was observed by digital microscope (503+ Guangzhou Haote optical instrument company). Fourier-transform infrared (FTIR) spectra are recorded by Smart iTR accessory of FTIR spectrometer (Thermo Fisher Nicolet iS10). Wide-angle X-ray diffraction (XRD) measurement was carried out on an XRD diffractometer (D8Advance, Bruker). The patterns with the $\mathrm{Cu} K \alpha$ radiation at $40 \mathrm{kV}$ and $30 \mathrm{~mA}$ were recorded in the region of $2 \theta$ from $5^{\circ}$ to $70^{\circ}$. TGA (STA 409 PC Luxx NETZSCH) was performed by heating samples to $700^{\circ} \mathrm{C}$ at $5^{\circ} \mathrm{C} / \mathrm{min}$ under a nitrogen flow.

\subsection{Adsorption Studies}

2.4.1. The Adsorption Ability Study. $0.1 \mathrm{~g}$ adsorbent was immersed into $80 \mathrm{~mL}$ methylene blue solution of $12.016 \mathrm{mg} \mathrm{L}^{-1}$ at $25^{\circ} \mathrm{C}$ for $36 \mathrm{~h}$ with $120 \mathrm{r} / \mathrm{min}$ controlled by a full temperature incubator shaker. The adsorption capacity $Q\left(\mathrm{mg} \mathrm{g}^{-1}\right)$ was calculated using the following equation:

$$
Q=\frac{\left(C_{0}-C_{e}\right) V}{m},
$$

where $C_{0}\left(\mathrm{mg} \mathrm{L}^{-1}\right)$ is the initial dye concentrations of the solutions, $C_{e}\left(\mathrm{mg} \mathrm{L}^{-1}\right)$ is the equilibrium dye concentrations of the solutions, $V$ (L) is the volume of the solution, and $m(\mathrm{~g})$ is the dried weight of the adsorbent [18]. Methylene blue concentration was measured at $664 \mathrm{~nm}$ using UV-Vis spectrophotometer (VARIAN Cary 50).

2.4.2. $\mathrm{pH}$ Variation. The initial $\mathrm{pH}$ of methylene blue solution $\left(12.016 \mathrm{mg} \mathrm{L}^{-1}\right)$ was adjusted by $0.1 \mathrm{~mol} \mathrm{~L}^{-1} \mathrm{HCl}$ or $\mathrm{NaOH}$ aqueous solutions to change between 2.06 and 9.93. $0.1 \mathrm{~g} \mathrm{AC2}$ was immersed into $80 \mathrm{~mL}$ of above solution for $36 \mathrm{~h}$ at $25^{\circ} \mathrm{C}$. The adsorption capacity was calculated based on (1).

2.4.3. Adsorption Kinetics. The change of adsorption capacity with time was measured. $0.5 \mathrm{~g}$ adsorbents $(\mathrm{AC1})$ were immersed into $200 \mathrm{~mL}$ methylene blue solution of $12.016 \mathrm{mg} \mathrm{L}^{-1}$ at $25^{\circ} \mathrm{C}$ with continuous shaking at $120 \mathrm{r} / \mathrm{min}$. At desired time intervals, $0.5 \mathrm{~mL}$ dyes solution was taken out to detect the current methylene blue concentration and $0.5 \mathrm{~mL}$ distilled water was added to the bulk solution to keep the volume constant. At time $t_{i}$, the adsorption capacity $Q\left(t_{i}\right)$ $\left(\mathrm{mg} \mathrm{g}^{-1}\right)$ was calculated using the following equation [18]:

$$
Q\left(t_{i}\right)=\frac{\left(C_{0}-C_{t_{i}}\right) V_{0}-\sum_{2}^{i-1} C_{t_{i-1}} V_{S}}{m}
$$

where $C_{t_{i}}\left(\mathrm{mg} \mathrm{L}^{-1}\right)$ is the dye concentration at time $t_{i} ; V_{S}$ is the volume of solution taken out each time for dye concentration analysis, and $m$ (g) represents the mass of the adsorbent [18].

2.4.4. Adsorption Equilibrium Study. 0.1g of AC2 was immersed into $80 \mathrm{~mL}$ methylene blue solution with concentration of $6.008 \mathrm{mg} \mathrm{L}^{-1}, 9.012 \mathrm{mg} \mathrm{L}^{-1}, 10.514 \mathrm{mg} \mathrm{L}^{-1}$, $12.016 \mathrm{mg} \mathrm{L}^{-1}$, and $15.02 \mathrm{mg} \mathrm{L}^{-1}$. Above five solutions were shook at $120 \mathrm{r} / \mathrm{min}$ at $25^{\circ} \mathrm{C}$ for $36 \mathrm{~h}$. Then the adsorption capacity $\left(Q_{e}\right)$ of each solution was measured based on (1). The same procedure was conducted at $30^{\circ} \mathrm{C}, 35^{\circ} \mathrm{C}, 40^{\circ} \mathrm{C}$, and $50^{\circ} \mathrm{C}$. Then the curves of $Q_{e}-C_{e}$ were plotted.

2.5. Reusability Property. The methylene blue-loaded AC1 and AC2 were immersed into $0.1 \mathrm{~mol} \mathrm{~L}^{-1} \mathrm{H}_{2} \mathrm{SO}_{4}$ aqueous solutions, washed with distilled water, and then reused in the next cycle of adsorption experiment. The adsorptiondesorption experiments were conducted for four cycles. All experiments were performed at $25^{\circ} \mathrm{C}$.

\section{Results and Discussion}

3.1. Preparation of Composite Particles. When used as adsorbent, attapulgite nanofiber usually suspends in solution, 


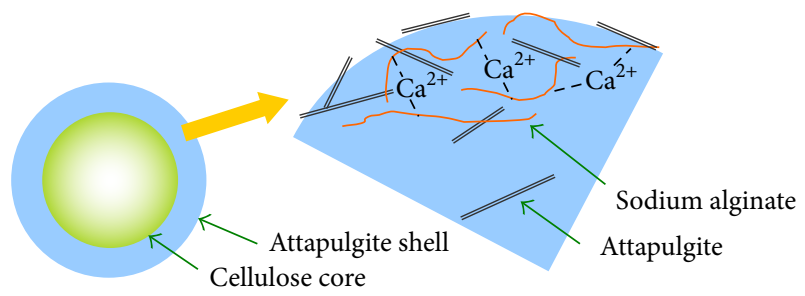

FIGURE 1: Schematic depiction of core-shell structure of celluloseattapulgite composite particle.

which leads to second pollution to water and difficulty of regeneration. In this study, attapulgite is mixed with sodium alginate solution and is coated on the surface of cellulose bead. Sodium alginate, derived primarily from brown seaweed, is a linear polysaccharide copolymer that consists of two sterically different repeating units, $\beta$-D-mannuronic acid (M) and $\alpha$-L-guluronic acid (G), in varying proportions [19]. Sodium alginate can be cross-linked by $\mathrm{Ca}^{2+}$ to form hydrogel. Above mixture is cross-linked by $\mathrm{Ca}^{2+}$ to form a hydrogel layer above the cellulose bead. After drying, the hydrogel becomes an attapulgite shell on the surface of cellulose core, preventing the second pollution of attapulgite powder. The structure of nanocomposite particle is shown in Figure 1.

Cellulose is selected to prepare the core for its low cost and being nontoxic and biodegradable. But cellulose is difficult to dissolve in usual solvent. In this study, we use $\mathrm{NaOH} /$ urea solution in low temperature as solvent to dissolve cellulose and to prepare cellulose bead as the core.

3.2. Morphology and Structure of Composite Particles. Figure 2(a) shows microscope image of AC2 and particle has a diameter of about $2 \mathrm{~mm}$ and has a core-shell structure. Figures 2(b)-2(f) show the SEM image of cross section and surface of composite particle. Figure 2(b) shows that the shell is adhered closely to the cellulose core and no obvious boundary is found. Figure 2(c) shows the coarse shell with thickness of $300 \mu \mathrm{m}$ (area between two white arrows). Figure 2(d) shows the aggregation area of attapulgite nanofibers (white arrow pointed). Aggregation areas of attapulgite indicate that the dispersion of attapulgite in shell is not well. The aggregation areas are enlarged in Figure 2(e), from which fibrous attapulgite is found. Figure 2(f) shows the pure sodium alginate area existing in the shell.

FTIR spectra of sodium alginate, attapulgite, and AC2 are shown in Figure 3. In the spectrum of AC2, $1421 \mathrm{~cm}^{-1}$ belongs to the symmetric stretch vibration of $\mathrm{C}=\mathrm{O}$ of sodium alginate. $3614 \mathrm{~cm}^{-1}$ is attributed to the stretching modes of hydroxyls coordinated with the magnesium. $3582 \mathrm{~cm}^{-1}$ and $3553 \mathrm{~cm}^{-1}$ belong to the symmetric and antisymmetric stretching mode of molecular water coordinated with the magnesium at the edges of the channels [20]. $1027 \mathrm{~cm}^{-1}$ belongs to $\mathrm{Si}-\mathrm{O}-\mathrm{Si}$ stretching vibration of attapulgite [21]. The results indicate that the shell is composed by sodium alginate and attapulgite. Smart iTR measures the surface structure of sample. So only the shell structure of composite particle can be detected.
Figure 4 shows the XRD peaks of attapulgite and attapulgite shell. Strong diffraction peak of $8.48^{\circ}$ is a typical peak of attapulgite corresponding to basal spacing of about $10.55 \AA$ and is attributed to the primary diffraction of the (110) crystal face. Other diffraction peaks are attributed as $\mathrm{d}(110)$ (10.55 $\AA), \mathrm{d}(200)(6.43 \AA), \mathrm{d}(130)(5.43 \AA), \mathrm{d}(040)(4.48 \AA)$, $\mathrm{d}(121)(4.14 \AA)$, and $\mathrm{d}(061)(2.55 \AA)$ [22]. All belong to the character peaks of attapulgite. The diffraction peaks of $26.54^{\circ}$ are attributed to intergrowth minerals of quartz in attapulgite. In attapulgite shell, no obvious shift of peak position indicates that the crystal structure of attapulgite has no change during mixing. Absence of diffraction peaks of sodium alginate revealed that sodium alginate exists as amorphous. XRD results confirmed that attapulgite is the main component of shell.

TG and DTG curves for the cellulose, attapulgite, and $\mathrm{ACl}$ are presented in Figure 5. The weight loss rate of $\mathrm{ACl}$ is between attapulgite and cellulose. For AC1, below $100^{\circ} \mathrm{C}$, the weight loss was ascribed to the removal of water which included surface water and zeolitic water of attapulgite. Between 200 and $300^{\circ} \mathrm{C}$, the rapid weight loss can be attributed to the decomposition of cellulose and sodium alginate. Above $300^{\circ} \mathrm{C}$, the weight loss corresponds to the degradation of residual decomposition products and loss of coordinated water and structural hydroxyl water in attapulgite [23]. The high residue mass of AC1 compared to the cellulose indicates the existence of attapulgite.

3.3. Adsorption Capacity. Figure 6 shows the adsorption effect of $\mathrm{ACl}$ (Figure 6(a), before adsorption; Figure 6(b), after adsorption). The slight color of Figure 6(b) reveals that the nanocomposite particles could effectively remove the methylene blue from water. The clear solution indicates that attapulgite nanocomposite prevents the second pollution of attapulgite nanofiber in water.

Figure 7 compares the adsorption capacities of nanocomposite particles (AC1, AC2, and AC3) with core-shell structure to contrast samples (cellulose bead, AC0, and AC4). Composite particles have better adsorption capacities compared to the adsorption capacities of cellulose bead, AC0, and AC4, which indicate that the shell of attapulgite nanofiber can effectively absorb methylene blue. The adsorption capacities of $\mathrm{AC1}, \mathrm{AC} 2$, and $\mathrm{AC} 3$ are higher than $\mathrm{AC} 0$ which only has a shell of sodium alginate, indicating the adsorption mainly resulted from attapulgite nanofiber. AC3 has maximum adsorption capacity of $9.1 \mathrm{mg} \cdot \mathrm{g}^{-1}$.

Attapulgite fiber is a kind of silicate with nanosized rodlike morphology and consists of two double chains of the pyroxene type $\left(\mathrm{SiO}_{3}\right)^{2-}$ like amphibole $\left(\mathrm{Si}_{4} \mathrm{O}_{11}\right)^{6-}$ running parallel to the fiber axis $[24,25]$. Attapulgite fiber has high surface area and moderate cation exchange capacity, which is useful for attapulgite as adsorbents to remove dye in wastewater. In addition, attapulgite fiber has negatively charged sorption sites because of isomorphic substitutions in structure. So attapulgite nanofiber can absorb cationic dyes through electrostatic attraction. The higher adsorption capacity of AC3 resulted from the high content of attapulgite nanofiber. From Figure 8, we can see that $\mathrm{ACl}$ has rare 


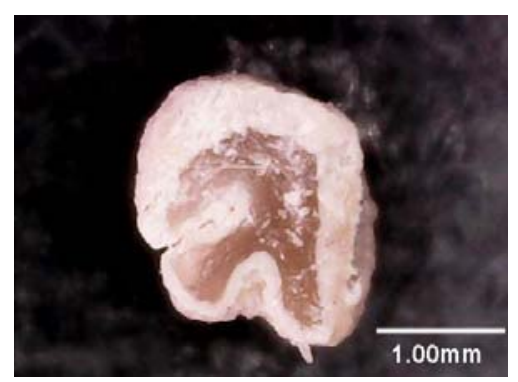

(a)

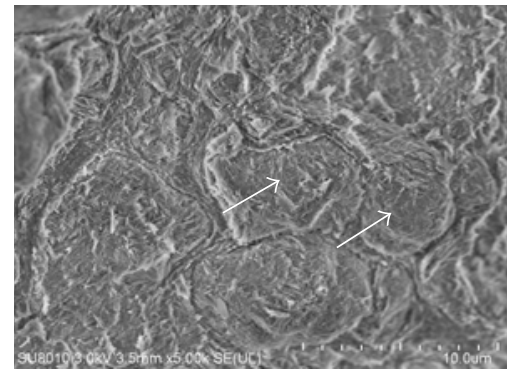

(d)

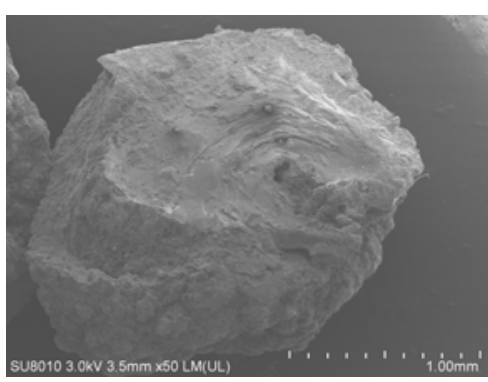

(b)

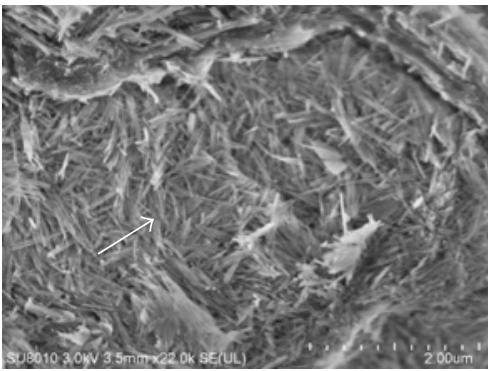

(e)

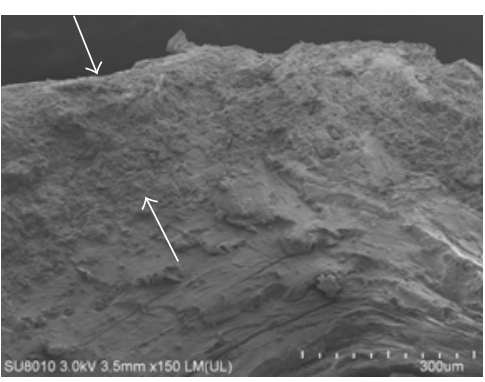

(c)

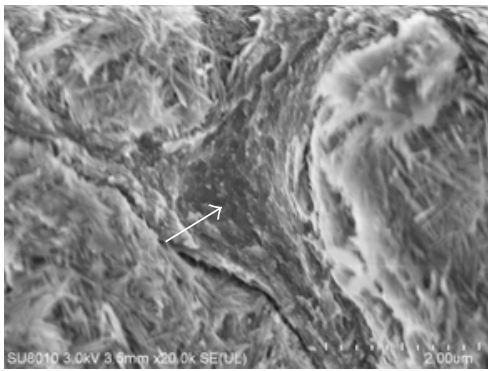

(f)

FIGURE 2: The morphology of the cellulose-attapulgite composite particles (AC2) ((a) cross section of particle by digital microscope; (b) cross section of particle by SEM; (c) shell structure of particle; (d) aggregation area of attapulgite; (e) amplified aggregation area of attapulgite; (f) area of sodium alginate).

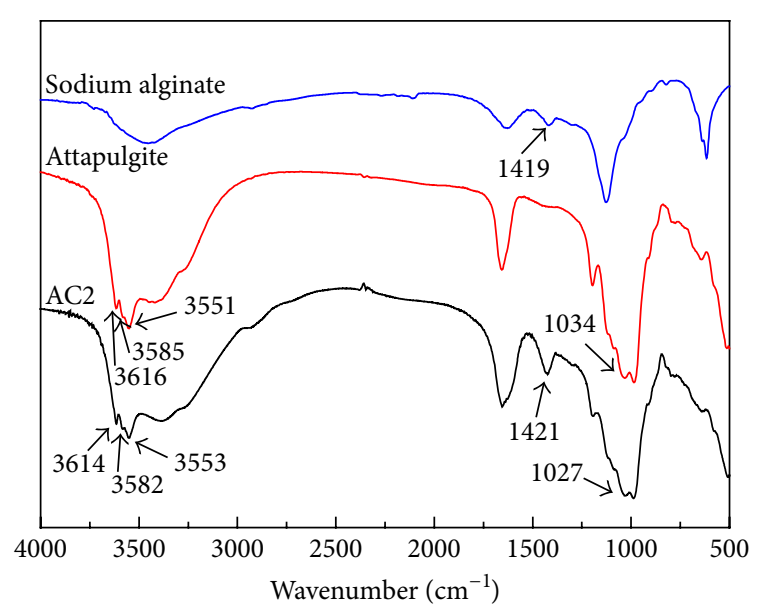

FIGURE 3: FTIR spectra of sodium alginate, attapulgite, and AC2.

dispersion of attapulgite nanofibers on the shell compared to AC2 and AC3, which leads to low adsorption capacity of AC1.

Other adsorption capacities for methylene blue have been reported, such as cross-linked porous starch $\left(9.46 \mathrm{mg} \mathrm{g}^{-1}\right)$ [26], sugar extracted spent rice biomass $\left(8.13 \mathrm{mg} \mathrm{g}^{-1}\right)$ [27], and attapulgite $\left(51 \mathrm{mg} \mathrm{g}^{-1}\right)$ [28]. Compared to attapulgite, the relative lower capacity of nanocomposite particle may have resulted in the aggregation of attapulgite on the shell which was observed by SEM photo (Figure 2(d)). The aggregation decreased the specific surface area of attapulgite and then decreased adsorption ability [29].

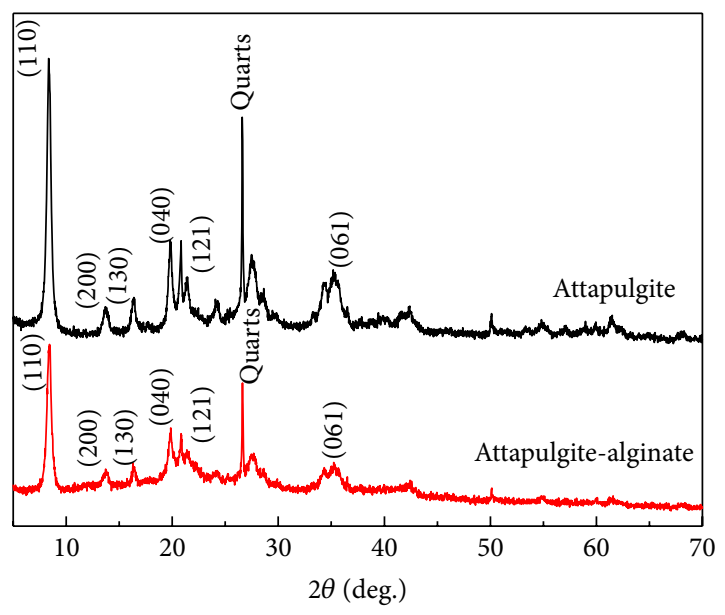

FIGURE 4: The powder X-ray diffraction pattern of the attapulgite and attapulgite shell.

3.4. Effects of $p H$ on the Adsorption. Figure 9 shows the adsorption capacity of AC2 in the $\mathrm{pH}$ range of 2.06 9.93. As the $\mathrm{pH}$ increased from 2.06 to 7.97 , adsorption capacity increased from 7.70 to $8.88 \mathrm{mg} \mathrm{g}^{-1}$; as the $\mathrm{pH}$ increased from 7.97 to 9.93 , adsorption capacity decreased from 8.88 to $8.43 \mathrm{mgg} \mathrm{g}^{-1}$.

For attapulgite, some isomorphic substitutions in the tetrahedral layer, such as $\mathrm{Al}^{3+}$ for $\mathrm{Si}^{4+}$, develop negatively charged sorption sites $\left(\mathrm{Si}-\mathrm{O}^{-}\right)$on the surface of attapulgite [30]. Si-O ${ }^{-}$can absorb cation dye through electrostatic attraction [30]. But, at low $\mathrm{pH}$, these negatively charged 

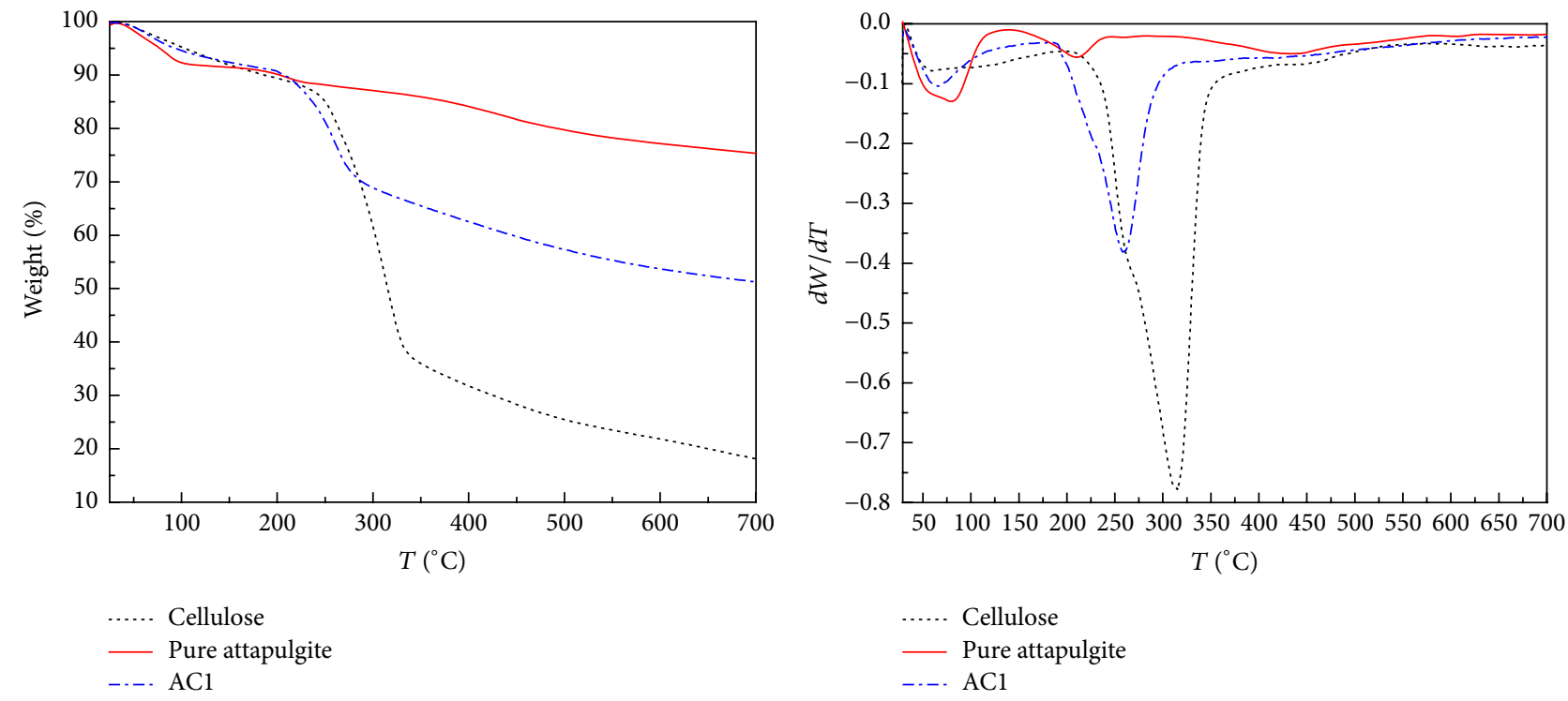

Figure 5: The TG and DTG of cellulose, attapulgite, and ACl.

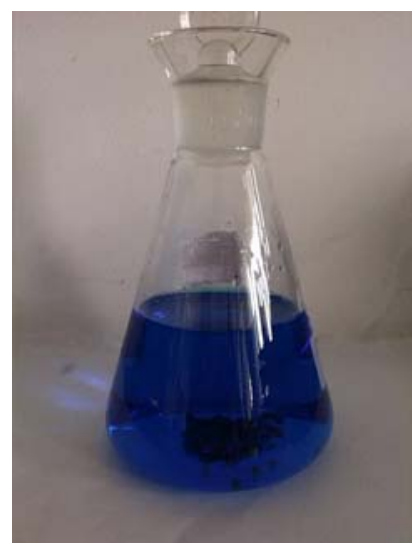

(a)

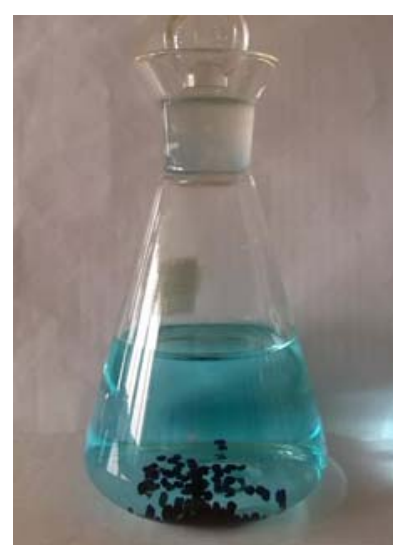

(b)

Figure 6: The methylene blue adsorption effect of $0.5 \mathrm{~g} \mathrm{ACl}$ in $200 \mathrm{~mL} 12.016 \mathrm{mg} \mathrm{L}^{-1}$ methylene blue solution for $48 \mathrm{~h}$ ((a) before adsorption and (b) after adsorption).

sorption sites are protonated to form $\mathrm{Si}-\mathrm{OH}_{2}{ }^{+}$by $\mathrm{H}^{+}$, which decrease the negative sites to attract methylene blue. As $\mathrm{pH}$ increases, protonated groups become less and negatively charged sites such as $\mathrm{Si}-\mathrm{O}^{-}$increase and favor the adsorption of cationic dye. In the alkaline $\mathrm{pH}$ range, the decreasing of adsorption capacity could be attributed to competition of $\mathrm{Na}^{+}$ ions for the negative adsorption sites [31].

3.5. Adsorption Kinetics. Time dependence of the adsorption capacity of $\mathrm{ACl}$ for methylene blue was tested to study the adsorption kinetics. The initial concentration of methylene blue is $12.016 \mathrm{mg} \mathrm{L}^{-1}$. The experimental results are shown in Figure 10. About $50 \%$ of methylene blue was adsorbed within $7 \mathrm{~h}$. The adsorption equilibrium was achieved after $36 \mathrm{~h}$. These results were similar to cross-linked porous starch

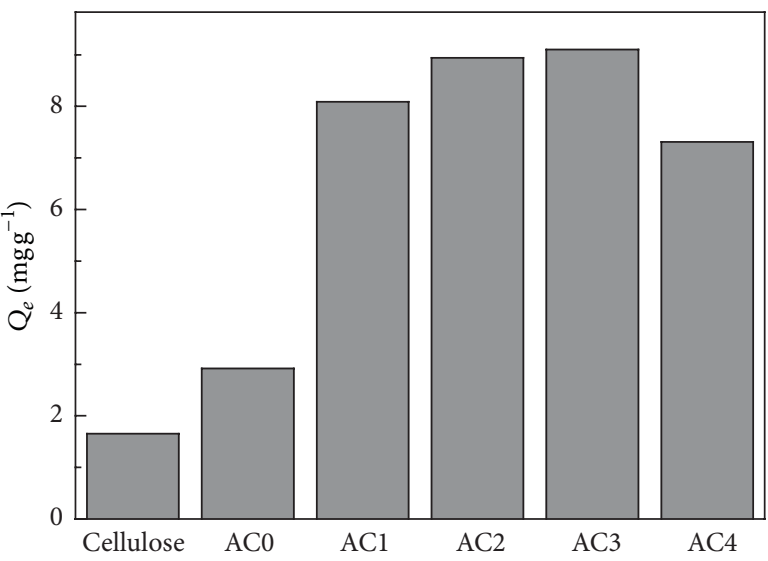

Figure 7: Adsorption capacity of six samples (cellulose bead, AC0, $\mathrm{AC} 1, \mathrm{AC} 2, \mathrm{AC} 3$, and AC4).

whose adsorption equilibrium was reached in about $30 \mathrm{~h}$ for methylene blue [26].

To further investigate the adsorption mechanisms, four common kinetic models were used to fit the data, namely, pseudo-first-order model [32], pseudo-second-order model [33], intraparticle diffusion models [34], and the Elovich equation [35]. Table 1 shows the equations of these models. In these models, $k_{1}$ is the rate constant first-order absorption $\left(\mathrm{min}^{-1}\right)$ [32]; $Q_{\mathrm{eq}}\left(\mathrm{mg} \mathrm{g}^{-1}\right)$ is the amount of dye adsorbed at equilibrium; $Q_{t}\left(\mathrm{mg} \mathrm{g}^{-1}\right)$ is the amount of dye adsorbed at any time $t(\mathrm{~min}) ; k_{2}\left(\mathrm{~g} \mathrm{mg}^{-1} \mathrm{~min}^{-1}\right)$ is the second-order rate constant [33]; $K_{T}\left(\mathrm{mgg} \mathrm{g}^{-1} \cdot \mathrm{min}^{1 / 2}\right)$ is the diffusion rate constant [34]; $C$ is a constant related to the thickness of boundary layer [34]; $a\left(\mathrm{mg} \mathrm{g}^{-1} \mathrm{~min}^{-1}\right)$ is the initial sorption rate [35]; $b\left(\mathrm{~g} \mathrm{mg}^{-1}\right)$ is the desorption constant related to the extent of surface coverage and activation energy for chemisorption [35]. 


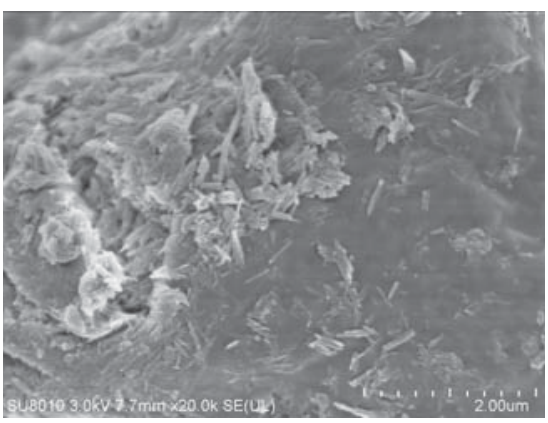

(a)

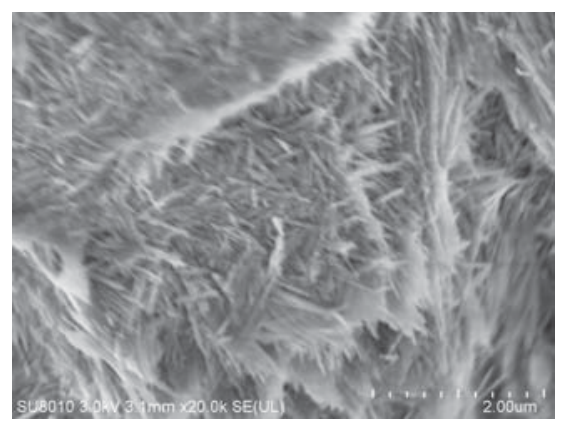

(b)

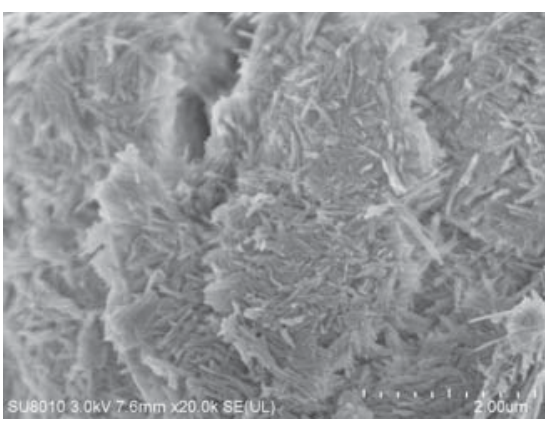

(c)

Figure 8: The surface morphology of the nanocomposite particles ((a) AC1; (b) AC2; (c) AC3).

TABLE 1: Kinetic models and their equations.

\begin{tabular}{llcc}
\hline Kinetic model & Equation & Plot & Reference \\
\hline Pseudo-first-order & $\log \left(Q_{\mathrm{eq}}-Q_{t}\right)=\log Q_{\mathrm{eq}}-k_{1} t$ & $\log \left(Q_{\mathrm{eq}}-Q_{t}\right)$ versus $t$ & {$[32]$} \\
Pseudo-second-order & $\frac{t}{Q_{t}}=\frac{1}{k_{2} Q_{\mathrm{eq}}^{2}}+\frac{1}{Q_{\mathrm{eq}}} t$ & $t / Q_{t}$ versus $t$ & {$[33]$} \\
Intraparticle diffusion & $Q_{t}=K_{T} t^{1 / 2}+C$ & $Q_{t}$ versus $t$ & {$[34]$} \\
Elovich equation & $Q_{t}=\left(\frac{1}{b}\right) \ln (a b)+\frac{1}{b} \ln t$ & $Q_{t}$ versus $\ln t$ & {$[35]$} \\
\hline
\end{tabular}

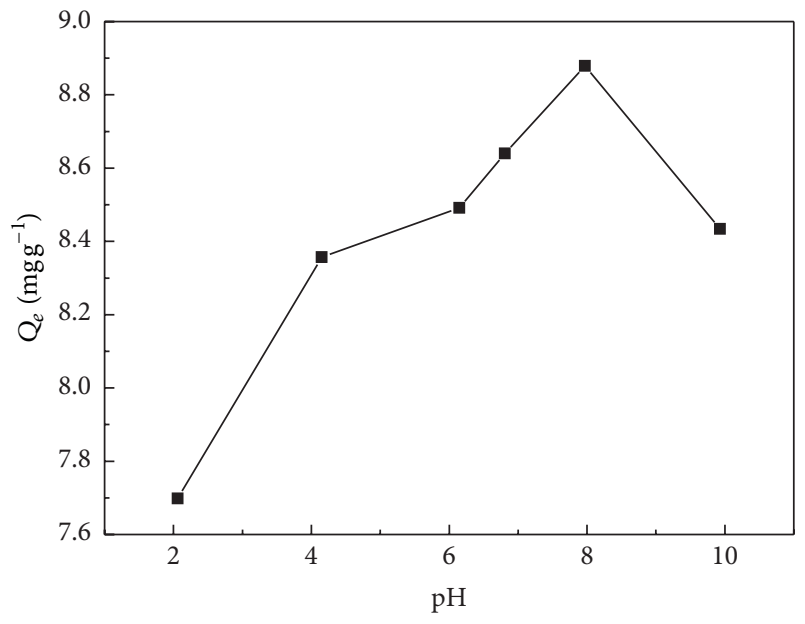

FIGURE 9: The influence of $\mathrm{pH}$ on the adsorption capacity of AC2 for methylene blue with concentration of $12.016 \mathrm{mg} \mathrm{L}^{-1}$ at $25^{\circ} \mathrm{C}$.

The pseudo-second-order model assumes that the rate limiting step is chemical sorption [36]. Elovich model recently has been found to be valid to describe the sorption kinetics of ion exchange systems [18]. The fitted parameters of these kinetic models are listed in Table $2 . R^{2}$ of the linear form for the various models suggests that the pseudo-first-order model is more suitable to describe the adsorption kinetic behavior. Using intraparticle diffusion model, plots of $Q_{t}$ versus $t^{1 / 2}$ do not pass through the origin indicating that the adsorption process is also controlled by film diffusion [36].

3.6. Adsorption Equilibrium Study. The equilibrium adsorption data is shown in Figure 11. At each temperature, adsorption capacity of AC2 for five different concentrations of

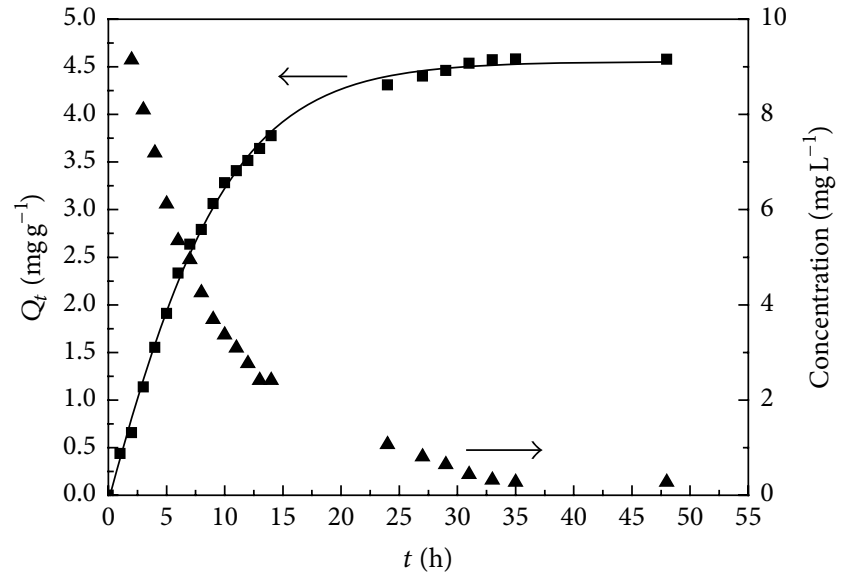

FIGURE 10: The absorbed capacity of $\mathrm{ACl}$ for methylene blue with concentration of $12.016 \mathrm{mg} \mathrm{L}^{-1}$ at $25^{\circ} \mathrm{C}$ and $\mathrm{pH}=7.0$ as a function of time ( $\mathbf{\square}$ represents experiment data; the full line represents fit of experimental data with a pseudo-first-order kinetic equation; $\boldsymbol{\Lambda}$ represents concentration of methylene blue in solution).

methylene blue was measured. The equilibrium adsorption data was correlated to four isotherm models: Langmuir [37], Freundlich [38], Sips [39], and Dubinin-Radushkevich [40]. Table 3 shows the equations of these models. In these models, $Q_{\max }$ is the maximum adsorption at monolayer coverage $\left(\mathrm{mg} \mathrm{g}^{-1}\right)$ [37]; $b$ is equilibrium constant $\left(\mathrm{mL} \mathrm{mg}^{-1}\right)$ in Langmuir adsorption [37] or Sips constant related to energy of adsorption in Sips model [39]; $K_{F}$ is the Freundlich characteristic constants [38]; $1 / n$ is the Freundlich characteristic constants [38]; $n$ could be regarded as the Sips parameter characterizing the system heterogeneity; $B$ is a constant 
TABLE 2: The kinetic parameters for MB adsorption onto AC1.

\begin{tabular}{|c|c|c|c|c|c|c|c|c|c|}
\hline \multirow{2}{*}{$T\left({ }^{\circ} \mathrm{C}\right)$} & \multicolumn{2}{|c|}{$\begin{array}{c}\text { Pseudo-first- } \\
\text { order } \\
\text { equation }\end{array}$} & \multicolumn{2}{|c|}{$\begin{array}{l}\text { Pseudo-second-order } \\
\text { equation }\end{array}$} & \multicolumn{2}{|c|}{ Intraparticle diffusion models } & \multicolumn{3}{|c|}{ Elovich equation } \\
\hline & $\begin{array}{c}k_{1} \\
\left(\min ^{-1}\right) \\
\end{array}$ & $R^{2}$ & $\begin{array}{c}k_{2} \\
\left(\mathrm{~g} \mathrm{mg}^{-1} \min ^{-1}\right)\end{array}$ & $R^{2}$ & $\begin{array}{c}K_{T} \\
\left(\mathrm{mgg}^{-1} \min ^{-1 / 2}\right)\end{array}$ & $R^{2}$ & 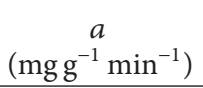 & $\begin{array}{c}b \\
\left(\mathrm{~g} \mathrm{mg}^{-1}\right)\end{array}$ & $R^{2}$ \\
\hline 25 & 0.11309 & 0.9952 & 0.01674 & 0.9779 & 0.7593 & 0.8746 & 1.3717 & 0.7705 & 0.9687 \\
\hline
\end{tabular}

TABLE 3: Isotherm models and their equations.

\begin{tabular}{llcl}
\hline Isotherm model & Equation & Plot & Reference \\
\hline Langmuir & $\frac{1}{Q_{\mathrm{eq}}}=\frac{1}{Q_{\max }}+\frac{1}{Q_{\max } b} \frac{1}{C_{e}}$ & $1 / Q_{\mathrm{eq}}$ versus $1 / C_{e}$ & [37] \\
Freundlich & $\ln Q_{\mathrm{eq}}=\frac{1}{n} \ln C_{e}+\ln K_{F}$ & $\ln Q_{\mathrm{eq}}$ versus $\ln C_{e}$ & [38] \\
Sips & $Q_{\mathrm{eq}}=\frac{Q_{m} b C_{e}^{1 / n}}{1+b C_{e}^{1 / n}}$ & $Q_{\mathrm{eq}}$ versus $C_{e}$ & {$[39]$} \\
Dubinin-Radushkevich & $\ln Q_{\mathrm{eq}}=\ln Q_{m}-B \varepsilon^{2}$ & $\ln Q_{\mathrm{eq}}$ versus $\varepsilon$ & {$[40]$} \\
\hline
\end{tabular}

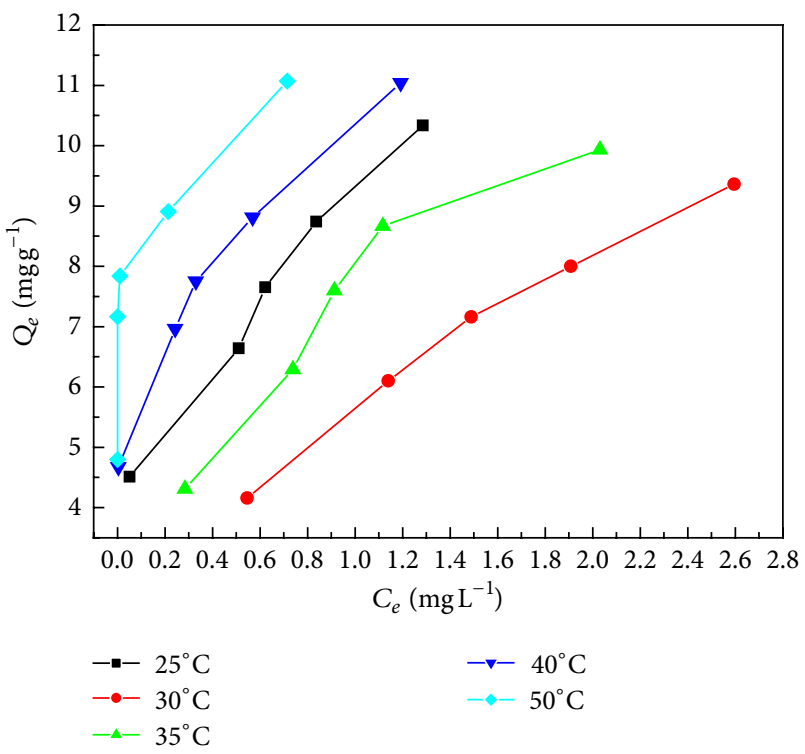

FIGURE 11: The curve of $C_{e}-Q_{e}$ of AC2 under different temperatures with duration time of $36 \mathrm{~h}$.

related to the mean free energy of adsorption per mol of the adsorbate $\left(\mathrm{mol}^{2} \mathrm{~J}^{-2}\right)[40] ; Q_{m}$ is the theoretical saturation capacity $\left(\mathrm{mg} \mathrm{g}^{-1}\right)$ [40]; $\varepsilon$ is the Polanyi potential [40], which is equal to $R T \ln \left(1+1 / C_{e}\right) ; R\left(\mathrm{~J} \mathrm{~mol}^{-1} \mathrm{~K}^{-1}\right)$ is the gas constant; $T(\mathrm{~K})$ is the absolute temperature.

The Langmuir isotherm model assumes the adsorption is monolayer adsorption [18]. A finite number of identical sites exist on a surface and all sites are energetically equivalent and there is no interaction between adsorbed molecules. Freundlich model is applied to describe that adsorption occurs on a heterogeneous surface. The fitting parameters of the above models are listed in Table 4. Most of the determination coefficients $\left(R^{2}\right)$ of the Langmuir model exceed 0.93 compared with those of the other models. This indicates that the Langmuir model is suitable to describe the adsorption behavior of AC2. So it can be concluded that methylene blue molecule is absorbed on the surface with monolayer. From Figure 11 , we can see that $C_{e}$ is almost near zero at $25^{\circ} \mathrm{C}, 40^{\circ} \mathrm{C}$, and $50^{\circ} \mathrm{C}$, which indicates that the particle can remove dye in very dilute aqueous solutions.

3.7. Regeneration Efficiency. Reusability is very important for adsorbent in practical applications. In current work, the adsorption and desorption processes were repeated for three cycles to measure the regeneration efficiency. $0.1 \mathrm{~mol} \mathrm{~L}^{-1}$ $\mathrm{H}_{2} \mathrm{SO}_{4}$ aqueous solution was used to recover the methylene blue loaded composite particles. Table 5 shows the adsorption capacities and the regeneration efficiency in each cycle. After three cycles, AC2 gets $94.64 \%$ recovery, indicating a high regeneration efficiency. This also illuminates that the adsorbent is suitable for practical applications.

\section{Conclusions}

The attapulgite nanofibers were coated onto the surface of cellulose bead to form nanocomposite particles with coreshell structure. SEM, FTIR, XRD, and TG all revealed that attapulgite nanofiber exists in the shell of nanocomposite particles. Nanocomposite particles have higher adsorption capacity than cellulose bead. Adsorption capacity is changed with $\mathrm{pH}$ of dye solution and largest adsorption capacity occurs at $\mathrm{pH}=8$. The adsorption equilibrium and kinetics study of composite particles indicate that the adsorption behavior follows Langmuir model and pseudo-first-order equation. Dye-loaded nanocomposite could be regenerated easily and high adsorption ability is reserved. Simple preparation, low cost, being easy to regenerate make the core-shell structured nanocomposite a suitable carrier for attapulgite and an attractive adsorbent for removal of the organic dyes from water. This study also proposes a new approach to use the attapulgite and cellulose as adsorption material. 
TABLE 4: The isotherms parameters for methylene blue adsorption onto AC2.

\begin{tabular}{|c|c|c|c|c|c|c|c|c|c|c|c|c|c|}
\hline \multirow{2}{*}{$T\left({ }^{\circ} \mathrm{C}\right)$} & \multicolumn{3}{|c|}{ Langmuir model } & \multicolumn{3}{|c|}{ Freundlich model } & \multicolumn{3}{|c|}{$\begin{array}{l}\text { Dubinin-Radushkevich } \\
\text { model }\end{array}$} & \multicolumn{4}{|c|}{ Sips model } \\
\hline & $\begin{array}{c}Q_{\max } \\
\left(\mathrm{mg} \mathrm{g}^{-1}\right)\end{array}$ & $\begin{array}{c}b \\
\left(\mathrm{~L} \mathrm{mg}^{-1}\right)\end{array}$ & $R^{2}$ & $1 / n$ & $\begin{array}{c}K_{F} \\
\left(\mathrm{mg} \mathrm{g}^{-1}\right)\end{array}$ & $R^{2}$ & $\begin{array}{c}Q_{\max } \\
\left(\mathrm{mg} \mathrm{g}^{-1}\right)\end{array}$ & $\begin{array}{c}E \\
(\mathrm{~kJ} / \mathrm{mol})\end{array}$ & $R^{2}$ & $\begin{array}{c}Q_{\max } \\
\left(\mathrm{mg} \mathrm{g}^{-1}\right)\end{array}$ & $b$ & $1 / n$ & $R^{2}$ \\
\hline 25 & 11.2284 & 4.6800 & 0.9365 & 0.2410 & 8.8710 & 0.9282 & 8.7615 & 6.3976 & 0.8012 & 123.1803 & 0.0795 & 0.2963 & 0.9153 \\
\hline 30 & 14.1965 & 0.7031 & 0.9875 & 0.5227 & 5.7221 & 0.9991 & 9.1354 & 2.0422 & 0.9360 & 51.6949 & 0.1252 & 0.5965 & 0.9992 \\
\hline 35 & 13.1130 & 1.5313 & 0.9801 & 0.4446 & 7.6222 & 0.9677 & 9.6025 & 2.9773 & 0.9125 & 16.70934 & 0.8786 & 0.7696 & 0.9677 \\
\hline 40 & 11.6023 & 8.7149 & 0.9721 & 0.1413 & 9.4353 & 0.9199 & 8.8507 & 12.1932 & 0.7702 & 151.0619 & 0.0699 & 0.1783 & 0.9006 \\
\hline 50 & 11.3469 & 36.8745 & 0.9940 & 0.0741 & 10.7578 & 0.8544 & 10.2382 & 16.4501 & 0.7087 & 320.9413 & 0.0351 & 0.0818 & 0.8492 \\
\hline
\end{tabular}

TABLE 5: Adsorption-desorption cycles of methylene blue.

\begin{tabular}{lccccc}
\hline Sample & Adsorption ability & First adsorption & Second adsorption & Third adsorption & Fourth adsorption \\
\hline \multirow{2}{*}{ AC1 } & Adsorption capacity $\left(\mathrm{mg} \mathrm{g}^{-1}\right)$ & 8.6317 & 8.5228 & 7.9651 & 7.6254 \\
& Recovery $(\%)$ & - & 98.74 & 92.28 & 88.34 \\
\hline \multirow{2}{*}{ AC2 } & Adsorption capacity $\left(\mathrm{mg} \mathrm{g}^{-1}\right)$ & 8.7754 & 8.6317 & 8.5707 & 8.3050 \\
& Recovery (\%) & - & 98.36 & 97.67 & 94.64 \\
\hline
\end{tabular}

\section{Competing Interests}

The authors declare that they have no competing interests.

\section{Acknowledgments}

The authors would like to thank the Natural Science Foundation for Colleges and Universities of Jiangsu Province (Grant no. 12KJD150006) for the financial support of this research.

\section{References}

[1] Y. Liu, P. Liu, Z. Su, F. Li, and F. Wen, "Attapulgite- $\mathrm{Fe}_{3} \mathrm{O}_{4}$ magnetic nanoparticles via co-precipitation technique," Applied Surface Science, vol. 255, no. 5, pp. 2020-2025, 2008.

[2] W. B. Wang and A. Q. Wang, "Nanocomposite of carboxymethyl cellulose and attapulgite as a novel $\mathrm{pH}$-sensitive superabsorbent: synthesis, characterization and properties," Carbohydrate Polymers, vol. 82, no. 1, pp. 83-91, 2010.

[3] B. Mu, Q. Wang, and A. Q. Wang, "Preparation of magnetic attapulgite nanocomposite for the adsorption of $\mathrm{Ag}^{+}$and application for catalytic reduction of 4-nitrophenol," Journal of Materials Chemistry A, vol. 1, no. 24, pp. 7083-7090, 2013.

[4] Y. Liu, W. B. Wang, Y. L. Jin, and A. Q. Wang, "Adsorption behavior of methylene blue from aqueous solution by the hydrogel composites based on attapulgite," Separation Science and Technology, vol. 46, no. 5, pp. 858-868, 2011.

[5] L. Wang, J. P. Zhang, and A. Q. Wang, "Fast removal of methylene blue from aqueous solution by adsorption onto chitosang-poly (acrylic acid)/attapulgite composite," Desalination, vol. 266, no. 1-3, pp. 33-39, 2011.

[6] Q.-H. Fan, P. Li, Y.-F. Chen, and W.-S. Wu, "Preparation and application of attapulgite/iron oxide magnetic composites for the removal of U(VI) from aqueous solution," Journal of Hazardous Materials, vol. 192, no. 3, pp. 1851-1859, 2011.

[7] M. Alexandre and P. Dubois, "Polymer-layered silicate nanocomposites: preparation, properties and uses of a new class of materials," Materials Science and Engineering R: Reports, vol. 28 , no. 1, pp. 1-63, 2000.
[8] K. Kabiri, H. Omidian, M. J. Zohuriaan-Mehr, and S. Doroudiani, "Superabsorbent hydrogel composites and nanocomposites: a review," Polymer Composites, vol. 32, no. 2, pp. 277-289, 2011.

[9] M. Shibayama, "Structure-mechanical property relationship of tough hydrogels," Soft Matter, vol. 8, no. 31, pp. 8030-8038, 2012.

[10] H. X. Yang, W. B. Wang, and A. Q. Wang, "A pH-sensitive biopolymer-based superabsorbent nanocomposite from sodium alginate and attapulgite: synthesis, characterization, and swelling behaviors," Journal of Dispersion Science and Technology, vol. 33, no. 8, pp. 1154-1162, 2012.

[11] P. Liu, L. P. Jiang, L. X. Zhu, and A. Q. Wang, "Attapulgite/ poly(acrylic acid) nanocomposite (ATP/PAA) hydrogels with multifunctionalized attapulgite (org-ATP) nanorods as unique cross-linker: preparation optimization and selective adsorption of $\mathrm{Pb}(\mathrm{II})$ Ion," ACS Sustainable Chemistry and Engineering, vol. 2, no. 4, pp. 643-651, 2014.

[12] M. Zhang, J. Soto-Rodríguez, I.-C. Chen, and M. Akbulut, "Adsorption and removal dynamics of polymeric micellar nanocarriers loaded with a therapeutic agent on silica surfaces," Soft Matter, vol. 9, no. 42, pp. 10155-10164, 2013.

[13] I.-C. Chen, M. Zhang, B. Teipel, I. S. De Araujo, Y. Yegin, and M. Akbulut, "Transport of polymeric nanoparticulate drug delivery systems in the proximity of silica and sand," Environmental Science and Technology, vol. 49, no. 6, pp. 35753583, 2015.

[14] S. Liu, D. Tao, T. Yu, H. Shu, R. Liu, and X. Liu, "Highly flexible, transparent cellulose composite films used in UV imprint lithography," Cellulose, vol. 20, no. 2, pp. 907-918, 2013.

[15] M. Zhang and M. Akbulut, "Adsorption, desorption, and removal of polymeric nanomedicine on and from cellulose surfaces: effect of size," Langmuir, vol. 27, no. 20, pp. 1255012559, 2011.

[16] J. Zhou, C. Chang, R. Zhang, and L. Zhang, "Hydrogels prepared from unsubstituted cellulose in $\mathrm{NaOH}$ /urea aqueous solution," Macromolecular Bioscience, vol. 7, no. 6, pp. 804-809, 2007.

[17] J. Cai, L. Zhang, J. Zhou et al., "Multifilament fibers based on dissolution of cellulose in $\mathrm{NaOH} /$ urea aqueous solution: 
structure and properties," Advanced Materials, vol. 19, no. 6, pp. 821-825, 2007.

[18] W. X. Zhang, H. Yang, L. Dong et al., "Efficient removal of both cationic and anionic dyes from aqueous solutions using a novel amphoteric straw-based adsorbent," Carbohydrate Polymers, vol. 90, no. 2, pp. 887-893, 2012.

[19] J. Han, Z. Zhou, R. Yin, D. Yang, and J. Nie, "Alginatechitosan/hydroxyapatite polyelectrolyte complex porous scaffolds: preparation and characterization," International Journal of Biological Macromolecules, vol. 46, no. 2, pp. 199-205, 2010.

[20] J.-H. Huang, Y.-F. Liu, Q.-Z. Jin, and X.-G. Wang, "Spectra study on the influence of drying process on palygorskite structure," Spectroscopy and Spectral Analysis, vol. 27, no. 2, pp. 408-410, 2007.

[21] Z. Lei, Q. Yang, S. Wu, and X. Song, "Reinforcement of polyurethane/epoxy interpenetrating network nanocomposites with an organically modified palygorskite," Journal of Applied Polymer Science, vol. 111, no. 6, pp. 3150-3162, 2009.

[22] C. Wang, Q. Wu, F. Liu et al., "Synthesis and characterization of soy polyol-based polyurethane nanocomposites reinforced with silylated palygorskite," Applied Clay Science, vol. 101, pp. 246252, 2014.

[23] W. Li, A. Adams, J. D. Wang, B. Blümich, and Y. G. Yang, "Polyethylene/palygorskite nanocomposites: preparation by in situ polymerization and their characterization," Polymer, vol. 51, no. 21, pp. 4686-4697, 2010.

[24] Y. Zhang, W. Wang, J. Zhang, P. Liu, and A. Wang, "A comparative study about adsorption of natural palygorskite for methylene blue," Chemical Engineering Journal, vol. 262, pp. 390-398, 2015.

[25] Y. Liu, W. Wang, and A. Wang, "Adsorption of lead ions from aqueous solution by using carboxymethyl cellulose-g-poly (acrylic acid)/attapulgite hydrogel composites," Desalination, vol. 259, no. 1-3, pp. 258-264, 2010.

[26] L. Guo, G. Y. Li, J. S. Liu, Y. F. Meng, and Y. F. Tang, "Adsorptive decolorization of methylene blue by crosslinked porous starch," Carbohydrate Polymers, vol. 93, no. 2, pp. 374-379, 2013.

[27] M. S. U. Rehman, I. Kim, and J.-I. Han, "Adsorption of methylene blue dye from aqueous solution by sugar extracted spent rice biomass," Carbohydrate Polymers, vol. 90, no. 3, pp. 1314-1322, 2012.

[28] A. Al-Futaisi, A. Jamrah, A. Al-Rawas, and S. Al-Hanai, "Adsorption capacity and mineralogical and physico-chemical characteristics of Shuwaymiyah palygorskite (Oman)," Environmental Geology, vol. 51, no. 8, pp. 1317-1327, 2007.

[29] G. Y. Tian, Y. R. Kang, B. Mu, and A. Q. Wang, "Attapulgite modified with silane coupling agent for phosphorus adsorption and deep bleaching of refined palm oil," Adsorption Science \& Technology, vol. 32, no. 1, pp. 37-48, 2014.

[30] H. Chen and J. Zhao, "Adsorption study for removal of Congo red anionic dye using organo-attapulgite," Adsorption, vol. 15, no. 4, pp. 381-389, 2009.

[31] M. T. Yagub, T. K. Sen, and M. Ang, "Removal of cationic dye methylene blue (MB) from aqueous solution by ground raw and base modified pine cone powder," Environmental Earth Sciences, vol. 71, no. 4, pp. 1507-1519, 2014.

[32] S. Lagergren, "About the theory of so-called adsorption of soluble substances," Kungliga Svenska Vetenskapsakademiens Handlingar, vol. 24, pp. 1-39, 1898.

[33] Y. S. Ho and G. McKay, "Sorption of dye from aqueous solution by peat," Chemical Engineering Journal, vol. 70, no. 2, pp. 115124, 1998.
[34] Y. A. Yahaya, M. Mat Don, and S. Bhatia, "Biosorption of copper (II) onto immobilized cells of Pycnoporus sanguineus from aqueous solution: equilibrium and kinetic studies," Journal of Hazardous Materials, vol. 161, no. 1, pp. 189-195, 2009.

[35] M. J. D. Low, "Kinetics of chemisorption of gases on solids," Chemical Reviews, vol. 60, no. 3, pp. 267-312, 1960.

[36] C. Duran, D. Ozdes, A. Gundogdu, and H. B. Senturk, "Kinetics and isotherm analysis of basic dyes adsorption onto almond shell (Prunus dulcis) as a low cost adsorbent," Journal of Chemical \& Engineering Data, vol. 56, no. 5, pp. 2136-2147, 2011.

[37] I. Langmuir, "The adsorption of gases on plane surfaces of glass, mica and platinum," The Journal of the American Chemical Society, vol. 40, no. 9, pp. 1361-1403, 1918.

[38] H. M. F. Freundlich, "Über die adsorption in lösungen," Zeitschrift für Physikalische Chemie, vol. 57, pp. 385-470, 1906.

[39] R. Sips, "On the structure of a catalyst surface," The Journal of Chemical Physics, vol. 16, no. 5, pp. 490-495, 1948.

[40] M. M. Dubinin, "Sorption and structure of active carbons: I. Adsorption of organic vapors," Zhurnal Fizicheskoi Khimii, vol. 21, pp. 1351-1362, 1947. 

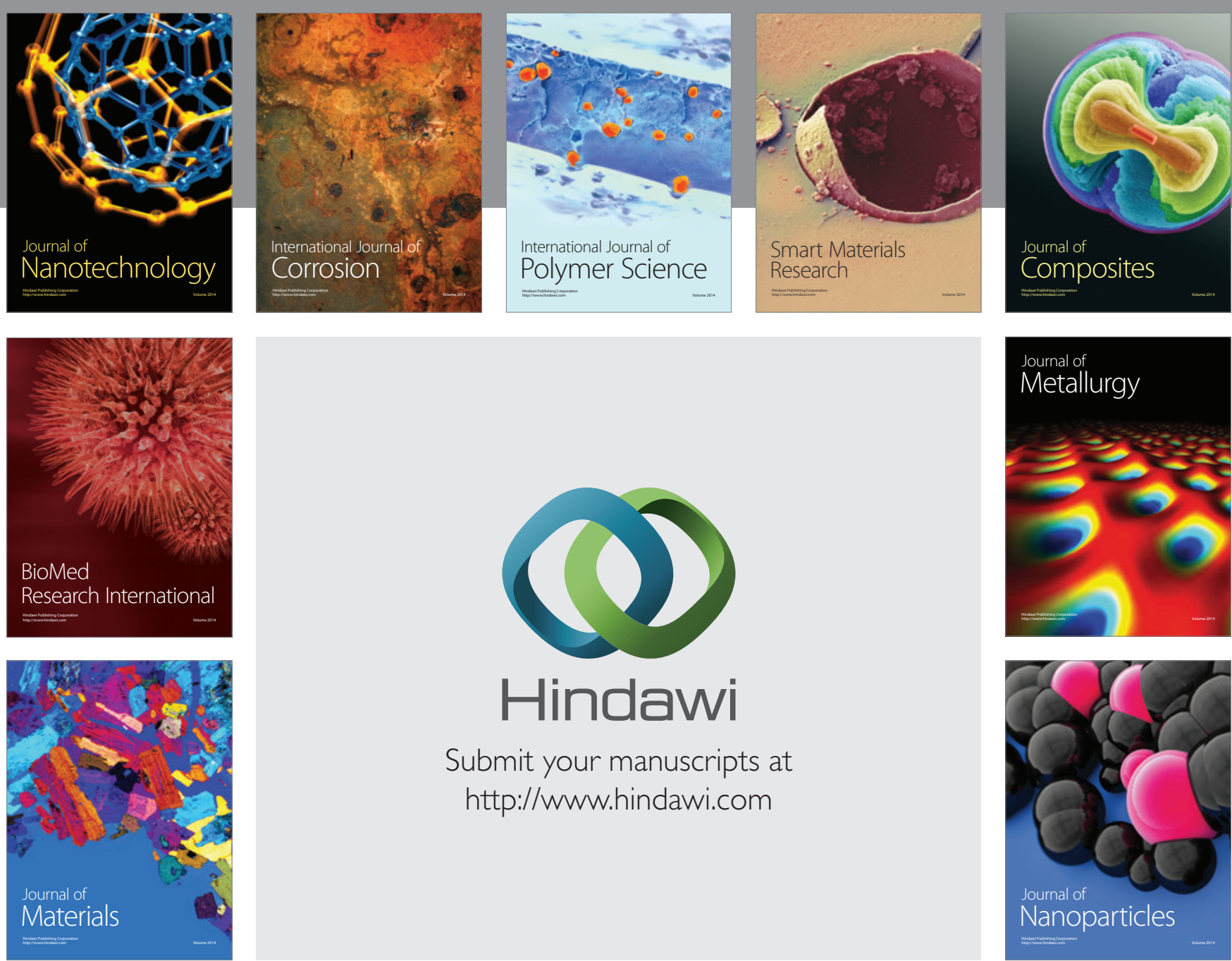

\section{Hindawi}

Submit your manuscripts at

http://www.hindawi.com

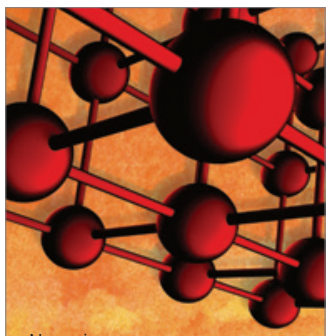

Materials Science and Engineering
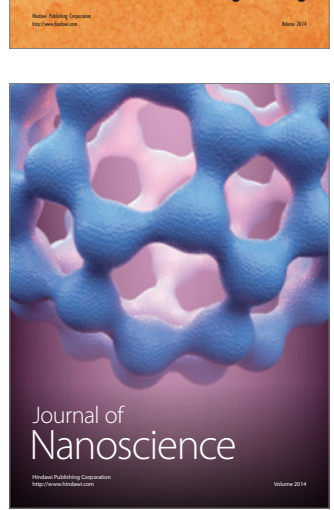
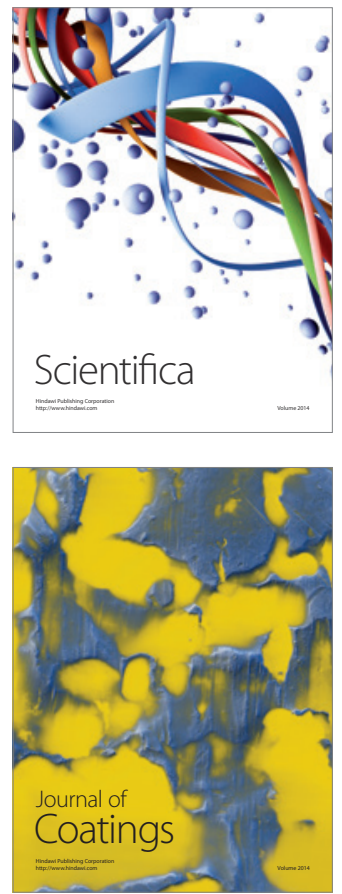
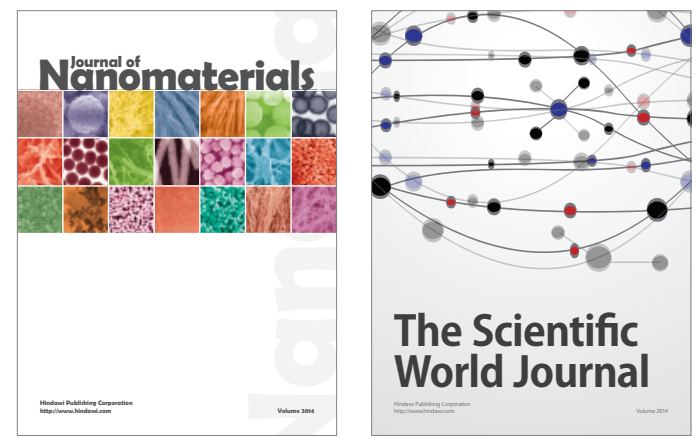

The Scientific World Journal
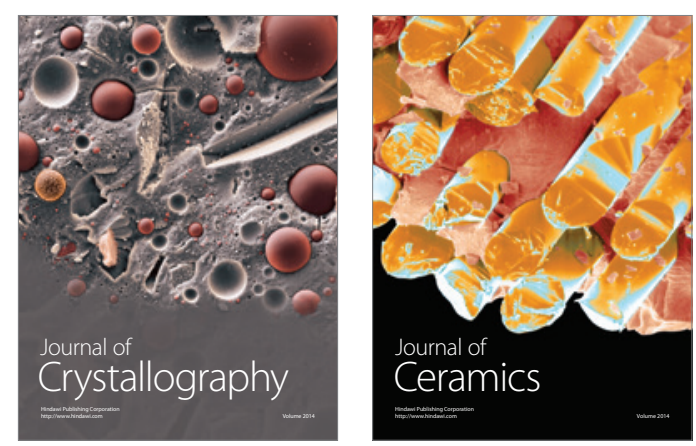
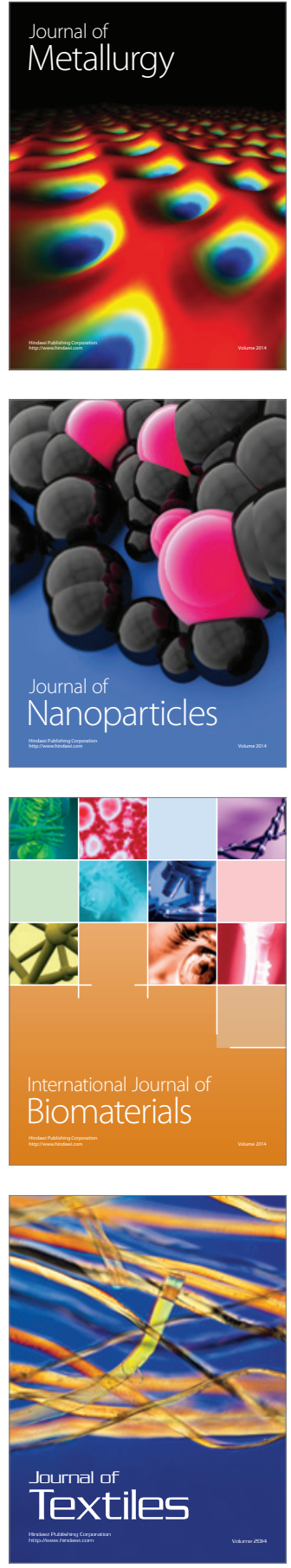